\title{
REFORMA 2011 EN MÉXICO, DERECHOS HUMANOS
}

Laura Patricia Chávez Flores ${ }^{1}$

\section{Resumen}

En México, reflexionar acerca de los Derechos Humanos, antes de la reforma a la Constitución Política de los Estados Unidos en el año 2011, resultaba un tema vinculado, para muchos, algo solo como un tema de torturas e incomunicaciones, una ilusión con respecto a que estos podrían ser respetados, para aquellos grupos vulnerables y sobre todo era imposible que la autoridad, pudiera ser vigilante activa, de una probable violación a los mismos, resultando ser como le llamamos los mexicanos un sueño guajiro, que algún día pudiéramos alcanzar la protección en el ámbito internacional. Es por esta razón que el articulo desarrolla los factores que llevaron a el país mexicano a La reforma que fue publicada en el Diario Oficial de la Federación, anunciaba la modificación a diversos y diferentes artículos de la Carta Magna, con diferentes directrices de acuerdo a las necesidades apremiantes de cada individuo, contemplándose como una garantía y goce de los Derechos Humanos, interpretados de conformidad con los tratados internacionales, mediante un control de convencionalidad, vinculándolos en aspectos de impartición y procuración de Justicia, área educativa, la obligatoriedad de los Servidores Públicos de dar la protección y reparación de violaciones a los derechos humanos bajo los principios de: universalidad, interdependencia, indivisibilidad y progresividad de estos, y así mismo la facultad de la Comisión Nacional de Derechos Humanos con facultades de Investigación, que antes esta facultad pertenecía a la Suprema Corte de Justicia de la Nación.

Palabras clave: Derechos humanos, Protección, Investigación.

$1 \quad$ Maestra en Derecho Orientación Penal de la Universidad de Guadalajara, Centro Universitario del Sur. Agente de Investigaciones en la Fiscalía del Estado de Jalisco, en el área de Homicidios Intencionales. Docente Investigadora del Centro Universitario del Sur, Guadalajara, México. Email: lpatychavez@gmail.com 


\section{Abstract}

In México, reflecting on human rights before the reform of the Political Constitution of the United States in 2011 was a linked issue, for many, something only as an issue of torture and incommunications, an illusion that these could be respected, for those vulnerable groups and above all it was impossible for the authority, could be active vigilant, a probable violation of them, resulting in what we Mexicans call a dream guajiro, that one day we could achieve protection in the international arena. The reform that was published in the Oficial Gazette of the Federation, announced the modification to diverse and different articles of the Magna Carta, with different guidelines according to the pressing needs of each individual, being contemplated as a guarantee and enjoyment of Human Rights, interpreted in accordance with internacional treaties, through a conventionality control, linking them in aspects of imparting and procuration of Justice, educational área, the obligation of Public Servants to give protection and reparation of human rights violations under the principles of: The National Human Rights Commission with powers of investigation, which previously belonged to the Supreme Court of Justice of the Nation.

Keywords: Human rights, Protection, Research. 


\section{Introducción}

Es indudable que esta reforma en el tema de Derechos humanos, ha sido una evolución jurídica, y un despertar de carácter internacional, relativas a la tutela de los Derechos Humanos en el ámbito interno, teniendo desde luego una influencia importante en las relaciones del ordenamiento con las de carácter internacional, como se ha mencionado con antelación, en relación a ese control de convencionalidad, donde instituciones como las Naciones Unidas, pero en especial en relación al sistema Interamericano de los Derechos Humanos, de forma particular con la Comisión y Corte Interamericana en esta materia, son garantes de la vigilancia de estos Derechos Humanos, ahora planetarios.

\section{La reforma en Materia de Derechos Humanos 10 de junio 2011}

Para hablar y poder entender, lo que dio origen a la referida reforma Constitucional, de los derechos humanos, donde fueron modificados diversos artículos de nuestra carta magna, es importante resaltar la universalidad de estos, y la trascendencia de aquel iusnaturalismo, siendo atribuible, a esos postulados, que referían que esos valores inherentes al ser humano eran adquiridos al nacer, y que la norma solamente se limitaría a consagrarlos mediante un Derecho Positivo.

La Constitución Mexicana de 1857, reconoce un decálogo amplio de los Derechos del Hombre, un término que quizá se asemejo más a los derechos humanos que los derechos fundamentales, y que estos a su vez presagiaban una nueva era de reconocimiento de los derechos inherentes al ser humano, sin embargo el termino garantías en el texto fundamental comulgo con las posturas iuspositivistas, al darle a los Derechos Constitucionales un carácter eminentemente jurídico positivo.

La Constitución vigente promulgada el 5 de Febrero de 1917, tomo un espíritu dogmático de su texto fundamental, de 1857, pero equipara el termino garantías individuales a derechos fundamentales, provocando confusiones terminologías entre constitucionalistas y derechos humanos, inherentes al ser humano por el simple hecho de existir y reconocidos en 
los instrumentos internacionales, se dieran en el estricto plano internacional sin fuerza coactiva por mucho tiempo.

El 10 de Junio de 2011, se publicó en el Diario Oficial de la Federación, durante el sexenio del Presidente Felipe Calderón Hinojosa, el decreto por el que se modificó la denominación del capítulo I del título primero, y se reformaron diversos artículos del texto, fundamental mexicano, estas reformas y modificaciones exponen el reconocimiento de la progresividad de los Derechos Humanos, mediante la expresión clara del principio pro persona, "con el cual se pretende favorecer y brindar la protección más estricta a todas las personas" (Coello \& Hernández, 2013, p.198.)

En la referida fecha de la publicación de la reforma, el Estado Mexicano había cumplido 12 años de haber aceptado una la competencia contenciosa de la Corte Interamericana de Derechos Humanos, y a su vez habían firmado y ratificado la mayor parte de tratados de derechos humanos, tanto en el sistema Interamericano de derechos humanos como del sistema universal de la Organización de las Naciones Unidas, en ese entonces en la Corte ya se habían ventilado los primeros 6 seis casos contenciosos, en los que el Estado mexicano, había sido declarado responsable internacionalmente de violaciones a Derechos Humanos.

Por lo que ante lo que estaba sucediendo en el sistema interamericano, en el estado mexicano, se llevaban procesos de apertura y de debate acerca de la necesidad de incorporar a la Constitución, los Derecho Humanos contenidos en los tratados internacionales, destacando la participación de académicos e instituciones de renombre.

En este sentido y siendo un país castrense, constantemente existieron y aún existen, violaciones de derechos Humanos, y desde luego la desaparición forzada, por ello la reforma constitucional considero, darle ciertas atribuciones a la Comisión de Derechos Humanos, teniendo las atribuciones de admitir reclamaciones de víctimas de violaciones de derechos Humanos, por parte de sus gobiernos, dado a que nuestro país como Estado miembro, ha permitido que la Comisión irrumpa y sea testigo del sin fin de violaciones que tras emitir, recomendaciones que terminan en indemnizaciones, que obviamente cuestan al Estado.

En los años 1971 - 1974, de la denominada guerra sucia, era inimaginable contar, con un pluralismo político, época caracterizada por la 
desaparición forzada, de un sin número de normalistas indígenas, y demás líderes estudiantiles en el Estado de Guerrero, que simplemente no estaban de acuerdo, con el manejo de la política y la educación en México, tal es el caso del señor Lucio Cabañas campesino, líder y profesor, quien pugnaba por que los niños no usaran uniformes escolares, sino tenían con que pagarlos, puesto que los pantalones no iba a ir a aprender, un ciudadano con ideales de libertad y de Justicia que fue perseguido por un Gobierno, por no comulgar con el mismo.

Durante el periodo del presidente Lázaro Cárdenas, ocurre detención y desaparición forzada el 25 de Agosto de 1974, del Señor Rosendo Radilla, ventilado ante la Corte Interamericana de Derechos Humanos, el caso de Radilla Pacheco vs México, donde su desaparición fue a raíz, de la persecución de Lucio Cabañas, que el señor Radilla, también estaba inmerso en la vida política activa dentro del Municipio de Atoyac de Álvarez, Guerrero, muchos de esa localidad fueron torturados para que informaran el paradero del maestro normalista Cabañas.

La detención y posterior desaparición forzada del señor Radilla Pacheco fue denunciada públicamente por la familia en el momento de sucedidos los hechos y posteriormente fue denunciada legalmente ante las instancias de procuración de justicia nacionales. Fue parte de la investigación realizada por la Comisión Nacional de Derechos Humanos la cual concluyó en un Informe especial publicado en el año 2001, ante la falta de respuesta por parte del Gobierno Mexicano en este mismo año fue presentado el caso ante la Corte Interamericana de los Derechos Humanos, admitiéndose en el año 2004, después de diversas sesiones, y emitiendo diversas recomendaciones al Estado Mexicano en el año 2008.

Finalmente, el 6 de julio de 2009, se llevó a cabo la Audiencia ante la Corte Interamericana de Derechos Humanos. El 23 de noviembre de 2009 la Corte, emitió la sentencia sobre el caso, condenando al Estado mexicano por graves violaciones a los Derechos Humanos, actualmente los peticionarios del caso se encuentran en el período de cumplimiento de la sentencia referida.

Por otra parte, a raíz del caso Radilla se han originado varios cambios estructurales que fueron ordenados en la misma sentencia de la Corte IDH. En la misma resolución de julio de 2011, la Suprema Corte estableció que 
los jueces militares no eran competentes para juzgar a militares acusados de violar derechos humanos, ordenando que dichos casos sean turnados a la justicia ordinaria federal.

En otra resolución de noviembre de 2011, la Suprema Corte estableció por primera vez la inaplicabilidad de la reserva de averiguaciones previas en casos de violaciones graves a derechos humanos, en cumplimiento a lo establecido en la Ley Federal de Transparencia y Acceso a la Información Pública Gubernamental, Por ello, la averiguación previa del caso Radilla es información pública a la que toda persona tiene derecho a tener acceso, dando parte aguas aun tema de actualidad como es la Transparencia a la que todos tenemos derecho como Ciudadanos.

El caso Radilla también resulta paradigmático en el derecho mexicano por establecer la obligación de adoptar estándares de derecho internacional en relación a la investigación y sanción de la desaparición forzada, Aunque la reforma respectiva en relación a dicho delito está también pendiente en el Congreso Federal, es de esperarse que las autoridades tomen en cuenta los criterios establecidos en la sentencia del caso Radilla para enjuiciar a los responsables de desaparición forzada, tema pendiente aún para nuestros Legisladores.

Así mismo y no menos importante resulta resaltar que como consecuencia de largas e intrincadas discusiones en el Gobierno Mexicano, a propósito de la sentencia del caso de Rosendo Radilla, y teniendo como marco la reforma constitucional en materia de derechos humanos, la Suprema Corte de Justicia, reconoció la obligación de los jueces mexicanos de realizar este control de convencionalidad, además de realizar algunas precisiones importantes:

Señaló la integración del parámetro de análisis del control de convencionalidad, mismo que se integra con:

1. Todos los derechos humanos contenidos en la Constitución Federal (con fundamento en los artículos lo. y 133), así como la jurisprudencia emitida por el Poder Judicial de la Federación;

2. Todoslosderechoshumanoscontenidosen Tratados Internacionales en los que el Estado mexicano sea parte. 
3. Criterios vinculantes de la Corte Interamericana de Derechos Humanos establecidos en las sentencias en las que el Estado mexicano haya sido parte, y criterios orientadores de la jurisprudencia y precedentes de la citada Corte, cuando el Estado mexicano no haya sido parte. (Rangel, 2011).

El año pasado, el 17 de Noviembre del 2017, en San José de Costa Rica, ante la Corte Interamericana de Derechos Humanos, México reconoce su responsabilidad en el caso de que 11 mujeres fueron violadas y ultrajadas por policías en San Salvador Atenco en el año 2006,en el caso, Mujeres de Atenco vs México, esto desde luego, es un tema trascendental, vinculante de un país, que después de una reforma en el tema, sigue siendo condenado por una instancia de carácter internacional, y que decir del tema de actualidad caso de los 43 desaparecidos, donde la Corte Interamericana de los Derechos Humanos, elegido 5 especialistas para investigar las cuestiones de investigación de las autoridades responsables, el último informe data del 04 de Mayo del 2018.

La interpretación de la ley suprema, claramente el hablar de los Derechos Humanos, (párrafo segundo del artículo $1^{\circ}$ de la Constitución), se aplicara en todo momento el principio pro persona, el cual se refiere a que en todo momento, que se apliquen las normas nacionales e internacionales, se aplicaran las más favorables a los derechos de las personas de acuerdo a cada caso concreto.

Elnuevotextoconstitucional, demandalanecesidad, de queelCongreso de la Unión, expida leyes reglamentarias para establecer los procedimientos necesarios para la reparación de los derechos Humanos por las autoridades nacionales, es decir de forma interna, acortando el tiempo para que la Justicia llegue, Ley Federal de Responsabilidad Patrimonial del Estado:

Los preceptos contenidos en el Capítulo II y demás disposiciones de esta Ley serán aplicables, en lo conducente, para cumplimentar los fallos de la Corte Interamericana de Derechos Humanos, de Derechos Humanos, aceptadas por los entes públicos federales y por el Estado Mexicano en su caso, en cuanto se refieran al pago de indemnizaciones así como las recomendaciones de la Comisión Nacional de los Derechos Humanos y de la Comisión 
Interamericana su caso, en cuanto se refieran al pago de indemnizaciones .(Legislativa, 2009)

\section{México, y la interacción con la corte interamericana de derechos humanos.}

Comenzaremos por destacar algunas aproximaciones de México en el sistema interamericano, que han sido a través de notables juristas mexicanos que formaron parte de la comisión, como lo fueron Gabino fraga y césar Sepúlveda, y recientemente José de Jesús Orozco Henríquez, e igualmente en la corte, Héctor Fix-Zamudio, así como Sergio García Ramírez, ambos se desempeñaron como juez y presidente de la misma, en su momento.

México tiene su primera aparición, en la Conferencia celebrada en Bogotá, Colombia, el 02 de Mayo de 1948, donde el tema vital y de importancia eran los Derechos Humanos, dicha reunión fue denominada, "Declaración Americana de los Derechos y deberes del Hombre", firmando en este acto la existencia y funcionamiento de la Comisión Interamericana de los Derechos Humanos, establecida bajo criterios de modelos europeos.

México, ratifica la firma con la C americana el 24 de marzo de 1981, pero admite la competencia contenciosa de la corte hasta el 16 de diciembre de 1998.la experiencia de nuestro país ante la corte interamericana, afortunadamente, no ha sido muy amplia, pero va en aumento. Existen varios expedientes relativos a medidas provisionales, y se han pronunciado a solicitud de nuestro país dos importantes opiniones consultivas, relativas al derecho de información sobre la asistencia consular en el marco de las garantías del debido proceso legal, y a la condición jurídica y derechos de los migrantes indocumentados, esto en adición a las sentencias condenatorias a que nos referiremos más adelante.

La Quinta reunión de consultado ministros de relaciones exteriores, se llevó a cabo en Santiago de Chile en 1959, iniciando su funcionamiento hasta el año de 1960, integrándose, por 7 miembros electos a título personal por la Asamblea General de la OEA (Organización de Estados Americanos), las características de los Estados miembros eran alta autoridad moral, y reconocida vocación en materia de Derechos humanos, actualmente la sede está en Washington D.C 
México, ha tenido participaciones importantes en la participación destacada en la conferencia Especializada Interamericana sobre Derechos Humanos, celebrada en la ciudad de San José, Costa Rica los días 7-22 de Noviembre de 1969, en la que estuvo dignamente representada por la delegación encabezada por el doctor Antonio Martínez Báez, muy destacado catedrático de Derecho Constitucional en la Facultad de Derecho de la Universidad Autónoma de México, analizando que desde tiempos remotos, los estudiosos del Derecho, quizá no esperaron una reforma en este sentido.

La relación de México, con y el Sistema Interamericano se produjo de una manera formal en 1986, ya que a proposición del Gobierno de nuestro país, auspiciado por el distinguido secretario de Relaciones Exteriores el destacado jurista mexicano Fernando Sepúlveda quien fungió como Juez, dentro de la Corte Interamericana de Derechos Humanos, aprobada por la mayoría de los representantes de los Estados Miembros, así mismo el Jurista Fix Zamudio fue designado como Juez de la Corte Penal Interamericana de Derechos Humanos, cargo que desempeño por un periodo de doce años, debido a una reelección en un segundo término en 1999, sustituido por Sergio García Ramírez propuesto por el Gobierno Mexicano y aprobado por los Estados Miembros de la Convención Americana de los Derechos Humanos.

El 07 de Junio del año 2011, mediante la Secretaria de Gobernacion, firmando tal considerando Jose Francisco Blake Mora, (2011) manifestó:

Que la Corte Interamericana de Derechos Humanos es el máximo órgano jurisdiccional en materia de derechos humanos en la región, Es una institución judicial autónoma de la Organización de los Estados Americanos cuyo objetivo es la aplicación e interpretación de la Convención Americana sobre Derechos Humanos y de otros tratados regionales concernientes al tema, México ratificó la Convención Americana sobre Derechos Humanos el 24 de marzo de 1981 y reconoció la competencia contenciosa de la Corte Interamericana de Derechos Humanos el 16 de diciembre de 1998. Desde esta última fecha, los fallos de ese Tribunal Internacional son jurídicamente vinculantes para el Estado Mexicano.

La vinculación del Gobierno Mexicano, con el sistema Interamericano, en relación a la representación de mexicanos en este Tribunal Internacional, 
culmino en el año 1998, cuando se reconoció expresamente la competencia jurisdiccional de la Corte Interamericana de Derechos Humanos, (García, S, 2011).

La Corte Interamericana ha dictado seis sentencias condenatorias para el Estado Mexicano, a) Caso Jorge Castañeda Gutman, sentencia del 6 de Agosto de 2008, b) Caso González y otras (Campos Algodonero), resuelto el 16 de Noviembre de 2009, c) Caso Radilla Pacheco, sentencia 23 de Noviembre del 2009, d) Cabrera García y Montiel Flores, el 26 de noviembre de 2010, e) el caso Rosendo Cantú y otra fallo, del 31 de Agosto 2010, resultando este ultimo en espera de la indemnización a las víctimas.

La reforma ha producido efectos jurídicos en aspectos de carácter internacional, que van más allá de los que afecten al sistema interamericano de Derechos Humanos, ya que el Estado mexicano, se ha vinculado por medio de diferentes tratados con diversas instituciones de solución de conflictos, tanto en el ámbito de las Naciones Unidas, además de las interamericanas, y si bien el Gobierno de nuestro país ha cumplido con algunas de las obligaciones con dichos organismos, en lo futuro debe regular de manera sistemática sus actividades para ajustarse a las nuevas disposiciones fundamentales internas, como lo mencionaba con antelación, maneras coercitivas de sanción.

La Suprema Corte de Justicia de la Nación, aun como tribunal Constitucional, no es competente para analizar, revisar, calificar o decidir si una sentencia dictada por la Corte Interamericana de Derechos Humanos es correcta o incorrecta, o si excede en relación con las normas que rigen su materia y proceso, así mismo no puede emitir ningún pronunciamiento con respecto a la validez de la misma, ya que dichas sentencias para el Estado Mexicano resultan ser cosa Juzgada, dado a la aceptación a sujetarse ante la Jurisdicción de la Corte, solo deberá cumplir con la sanción impuesta.

Las resoluciones por la Corte Interamericana de Derechos Humanos, referidas son obligatorias para todos los órganos del Estado Mexicano, al haber figurado como parte en un litigio concreto, siendo vinculantes para el Poder Judicial no sólo los puntos de resolución concretos de la sentencia, sino la totalidad de los criterios contenidos en ella.

Los criterios de la Corte Interamericana de Derechos Humanos (CIDH) que derivan de sentencias en donde el Estado Mexicano no intervino como parte en el litigio, son orientadores para todas las decisiones de los jueces 
mexicanos, siempre que sean más favorables a la persona bajo el principio pro persona, de conformidad con el artículo lo. constitucional, y atendiendo a los criterios interpretativos de la Corte Interamericana para evaluar si existe alguno que resulte más favorable y procure una protección más amplia del derecho que se pretende proteger de acuerdo al principio pro hominie.

La finalidad de la reforma constitucional de 10 de junio de 2011, fue la de seguir la tendencia internacional de que los Estados busquen las condiciones propicias para la ampliación de los derechos humanos, que las autoridades generen la responsabilidad de que dentro de ámbito de sus competencias, tienenlaobligación de promover, respetar, protegerygarantizar los derechos humanos de conformidad con los principios de universalidad, interdependencia, indivisibilidad y progresividad. En consecuencia, el Estado deberá prevenir, investigar, sancionar y reparar las violaciones a los derechos humanos, en los términos que establezca la ley.

La influencia de los criterios de la Corte Interamericana de Derechos Humanos, también puede tener una recepción inadecuadaen elordenjurídico interno, pues criterios como los que ahora se analizan, enarbolan sentencias dictadas por ese Tribunal Constitucional, con el pretexto de que al haberlo sustentado un órgano de esa naturaleza, ello tiene una fuerza definitiva en el régimen interno, lo que desde luego no puede ser así, porque sería tanto como desconocer que cada nación de acuerdo a su circunstancia social, económica, cultural e incluso ideológica, guarda particularidades frente a las otras.

La reforma en materia de Derechos Humanos, implico que una reestructuración de unsistemaen elcual constantementese violaban Derechos Humanos, a diestra y siniestra, donde ante la existencia de una Comisión Nacional de Derechos Humanos en México, como órgano de vigilancia y de protección, pero mas no de acción, nos hace estar aun en el ojo del huracán con las múltiples desapariciones forzadas, las torturas por parte policías, y las diversas violaciones a los Derechos Humanos cada a día parece estar en declive, por ello ha resultado larga la espera, para que un caso llegue a conocimiento de la corte, pero efectivo en el tema de sanción pecuniaria, en caso de encontrarse responsable al Estado mexicano, que al final es en quien recae la inoperancia de las Instituciones.

Sin duda alguna, esta reforma ha logrado las fibras mas sensibles de quienes integran nuestra honorable Suprema Corte de Justicia de la Nación, 
en máximo Órgano, nuestro Tribunal Constitucional, donde los señores ministros en sus ponencia, retoman en cada uno de los puntos la importancia de los Derechos Humanos.

El pasado 28 de Junio del 2018, el señor ministro Luis María Aguilar Morales, Presidente de la Suprema Corte de Justicia de la nación y del Consejo de la Judicatura federal, emitió un discurso en la clausura de una Maestría en Derechos Humanos, dirigido a los Servidores públicos de la suprema corte de justicia de la nación, emitió un discurso elocuente en tema de los derechos humanos, que es importante citar:

Estamos frente a una amenaza existencial para los derechos humanos y un peligro real para la humanidad. Por ello, tal como hesostenidoendistintosforos, no puedehaber, porningún motivo y bajo ninguna circunstancia, marcha atrás en la protección de los derechos humanos. Tan es así, que la Suprema Corte, nuestro Tribunal Constitucional, ha reiterado que el principio de progresividad — previsto en el artículo $1^{\circ}$ constitucional, y en diversos tratados-, ordena ampliar el alcance y la protección de los derechos humanos en la mayor medida posible hasta lograr su plena efectividad, de acuerdo con las circunstancias fácticas y jurídicas.(Aguilar, 2018)

\section{Conclusiones}

Las reformas en materia constitucional, y de forma muy especial la del denominada como la reforma de los Derechos Humanos realizada en el año 2011, es la reforma de transformación que vincula a México, con un tema universal, en el plano de Justicia Internacional, dado al poder de atracción otorgada a Tribunales de Justicia Internacional, siendo un país de tratados y convenios, de apertura, que se sujeta a parámetros internacionales y atiende a sus recomendaciones, puntualizando que la Corte Interamericana de Derechos Humanos, la Corte Penal Internacional, y otros organismos tutelan en todo momento los Derechos Humanos, ahora respetados y reconocidos por el artículo 1 de la Constitución Política de los Estados Unidos Mexicanos. 
En este momento debemos analizar, que tenemos la oportunidad como ciudadanos y profesionales, hacer valer el acceso y respeto a los Derechos Humanos, por aquellos grupos vulnerables, que aun no tienen un acceso a la Justicia, y que como conocedores de la reforma, debemos promocionarla, como lo mencione con antelación, hoy, nuestro máximo órgano de Justicia la Suprema Corte de Justicia de la Nación, hoy en día emite criterios basados en el principio pro persona, respeto irrestricto a los derechos fundamentales de la persona.

Las reformas constitucionales en todo momento deben ir encaminadas a favorecer a cada uno de los ciudadanos que habitan nuestro territorio nacional, la evolución de una norma, nace cuando se analiza, se critica y se entiende, sobre todo se exige con los parámetros permitidos, siempre deberá prevalecer el bien común y la paz social en un Estado, nuestra constitución, data de muchos años de creación, pero las necesidades de la Nación, han dado paso a las reformas y así seguirá mutando por que el mundo, cambia minuto a minuto, y los que se encuentren en la tarea de emitir la norma deberán estar atentos a los cambios socio culturales. "En un mundo globalizado, quizá el respeto a los derechos Humanos podría ser la formula de una paz social".

\section{Referencia}

Rangel Hernández, Laura. (2011). Sentencias condenatorias al Estado mexicano dictadas por la Corte Interamericana de Derechos Humanos y sus implicaciones en el orden jurídico nacional. Revista IUS, 5(28), 160-186. Recuperado en 31 de julio de 2018, de http://www.scielo.org.mx/scielo.php?script=sci_arttext\&pi$\mathrm{d}=$ S1870-21472011000200008\&lng=es\&tlng=es.

García, Ramírez, Sergio, México (2011), México y la Corte Interamericana de Derechos Humanos, Recuperado en 31 de Julio de 2018, https:// archivos.juridicas.unam.mx/www/bjv/libros/6/2607/4.pdf.

Fix- Zamudio, Hector, México (2011), Reformas Constitucionales Mexicanas de junio 2011, Recuperado en 31 de Julio de 2018, www.juridicas, unam.mx.

Fix- Zamudio, Héctor, (2011). México y la Corte Penal Interamericana de Derechos Humanos, en México Comisión Nacional de los Derechos Humanos, Sergio García Ramírez México (2011), “Administración 
de la Competencia Contenciosa de la Corte Interamericana de los Derechos Humanos.

Conferencia especializada sobre Derechos Humanos. Actas y documentos, Washington D.C. Secretaria General - Organización de los Estados Americanos, reimpresión 1978. Conferencia en la que pronunció un discurso Gabino Fraga, entonces presidente de la Comisión Interamericana.

Aguilar Morales Luis, (2018), Ceremonia de Final de Cursos de la Maestria en Derechos Humanos, Suprema Corte de Justicia de la Nacion. Recuperado 01 de agosto de 2018,

www.scjn.gob.mx/sites/default/files/discurso_ministro/documento/2018-06/28JUN18-

\section{Legislativa}

Ley federal de responsabilidad patrimonial del estado cámara de diputados del H. Congreso de la unión. Secretaría General Secretaría de Servicios Parlamentarios Última Reforma DOF 12-06-2009 2 de 10 de Derechos Humanos, aceptadas por los entes públicos federales y por el Estado Mexicano en su caso, en cuanto se refieran al pago de indemnizaciones."

Constitución Política de los Estados Unidos Mexicanos. 